\title{
Respostas de cultivares de algodão ao cloreto de mepiquat aplicado via embebição de sementes
}

\author{
Getúlio Takashi Nagashima ( $\left.{ }^{*}\right)$; Frederico Thomaz Santos ('); Édison Miglioranza (') \\ (') Universidade Estadual de Londrina - UEL, CCA, Departamento de Agronomia, Rodovia Celso Garcia Cid, km 380, 86051-990 \\ Londrina (PR).E-mail: gtnagashima@yahoo.com.br (*) Autorcorrespondente.fredericoagro@hotmail.com; emiglior@uel.br
}

Recebido: 29/abr./2009; Aceito: 24/jun./2010

\section{Resumo}

As recomendações de reguladores de crescimento cloreto de mepiquat (CM) geralmente não consideram as diferenças entre cultivares de algodoeiro utilizadas para o cultivo. O trabalho teve como objetivo avaliar o crescimento e o desenvolvimento de cultivares de algodão ante a embebição das sementes com regulador de crescimento cloreto de mepiquat, visando à sua caracterização quanto à resposta ao tratamento. Foram utilizadas as cultivares IPR-120, IAC-24, CD-405, Delta Opal e Fibermax 966, cujas sementes foram embebidas em solução contendo 2,0 g de cloreto de mepiquat para cada $100 \mathrm{~mL}$ de água deionizada por 12 horas e cultivadas em vaso, em casa de vegetação. Foram avaliadas: a altura de plantas, a altura da inserção do nó cotiledonar, o diâmetro caulinar, a área foliar e a massa da matéria seca da parte aérea. As cultivares tiveram resultados diferenciados ao tratamento de sementes via embebição com regulador de crescimento, sendo as cultivares Fibermax 966, Delta Opal e CD 405 as mais sensíveis. O tratamento foi eficiente na redução do porte, da inserção do nó cotiledonar, da área foliar e da massa da matéria seca da parte aérea do algodoeiro, além de alterar a partição dos assimilados, comparadas com plantas originadas de sementes sem tratamento.

Palavras-chave: Gossypium hirsutum r. latifolium, pix, partição de assimilados, redução de crescimento.

\section{Response of cotton cultivars to mepiquat chloride applied by soaking seed}

\begin{abstract}
Recommendations for use of the plant growth regulator Mepiquat Chloride (MC) usually do not consider differences among cotton cultivars. The objective of this research was to evaluate the growth and development of cotton cultivars after seed soaking with Mepiquat Chloride. The cultivars used were IPR-120, IAC-24, CD-405, Delta Opal e Fibermax 966, whose seeds were soaked in a solution containing $2.0 \mathrm{~g}$ of Mepiquat Chloride diluted in $100 \mathrm{~mL}$ of deionized water during 12 hours. Seeds were sown in pots and plants were grown under greenhouse conditions. The parameters evaluated were plant height, height of the cotyledon node insertion, stem diameter, leaf area and shoot dry matter. The cultivars presented differential responses to growth regulator, being cultivars Fibermax 966, Delta Opal and CD 405 the most sensitive. The treatment was effective in reducing the plant height and cotyledon node insertion, leaf area and shoot dry matter. Assimilates partitioning was also affected when comparing control and treated plants.
\end{abstract}

Key words: Gossypium hirsutum r. latifolium, pix, assimilates partitioning, growth reduction.

Com as profundas transformaçôes ocorridas no sistema de produção na cultura do algodoeiro, o cultivo em condiçóes sem estresse hídrico e nutricional produz excessiva vegetação, o que interfere negativamente na produção final. Nesses casos, torna-se imprescindível a manipulação da arquitetura das plantas do algodoeiro com reguladores de crescimento, sendo esta uma das estratégias agronômicas incorporadas no processo de produção desta cultura com o objetivo de melhorar os atuais níveis de produtividade e reduzir custos (REDDY et al., 1992; Lamas et al., 2000).

O uso de reguladores de crescimento é comum na produção de algodão utilizando cultivares comerciais, e o efeito da interação desses reguladores com diferentes cultivares não é totalmente compreendido (JoHNSON e Pettigrew, 2006). York (1983), estudando o efeito do regulador de crescimento em 14 cultivares via aplicação foliar, concluiu que a seleção das cultivares náo deve ser levada em consideração para a decisão de uso de reguladores de crescimento. Entretanto, mais recentemente, algumas pesquisas têm demonstrado que cultivares de algodão respondem diferentemente à aplicação do CM (Zanqueta et al., 2004). Segundo O'Berry et al. (2009), a variação nas respostas de cultivares à aplicação de regulador de crescimento poderá resultar em recomendaçôes mais refinadas e estudos futuros poderão salientar os efeitos sobre características de crescimento e produção de diferentes grupos de maturação. 
O uso do CM via aplicação na semente apresenta viabilidade para a introdução da cultura em altas densidades de semeadura, com redução do porte da planta desde a emergência. A utilização do regulador de crescimento via sementes permite vantagens, pois não há riscos de perdas por ocorrência de chuvas após pulverização e nem risco de contaminação ambiental devido a deriva da aplicação foliar.

Os trabalhos de Corbin Jr. e Frans (1991), Nagashima et al.(2005) e Lamas (2006) demonstraram que o tratamento da semente de algodáo com $\mathrm{CM}$, nas doses estudadas, reduzem o crescimento da planta, especialmente entre a emergência e o florescimento.

Contudo, na literatura não foram encontrados trabalhos sobre a resposta de diferentes cultivares de algodão ao $\mathrm{CM}$ aplicado às sementes. Assim, o presente estudo teve como objetivo avaliar o desenvolvimento de cultivares de algodão ante o tratamento das sementes via embebição, com soluçáo de cloreto de mepiquat.

$\mathrm{O}$ experimento foi realizado em casa de vegetação, e foram utilizadas sementes das cultivares IPR-120, FIBERMAX 966 e DELTA OPAL, de ciclo médio e altura média de planta de 1,08; 1,10 e 1,70 m respectivamente, e as cultivares CD-405 e IAC-24, de ciclo tardio e porte médio de 1,22 m e porte alto respectivamente. Para a embebição, as sementes foram colocadas entre 2 folhas de papel tipo "germitest" umedecidas na proporção de 2,5 vezes sua massa seca, em soluçáo de CM na concentração de 2,0 g do princípio ativo para cada $100 \mathrm{~mL}$ de água deionizada, à temperatura de $20 \pm 0,5^{\circ} \mathrm{C}$, por 12 horas. Em seguida, as sementes foram secas à sombra, em local ventilado, por 48 horas. As testemunhas não receberam tratamento algum.

A semeadura foi realizada com cinco sementes por vaso, à profundidade de $3 \mathrm{~cm}$, separadas entre si e, após a emergência, houve desbaste, mantendo-se uma planta por vaso. O substrato utilizado foi Latossolo Vermelho distroférrico (2 L por vaso), adubado com 5,0 $\mathrm{g}$ da fórmula 08-28-16 para cada vaso.

Aos 59 dias após emergência (DAE), na mudança da fase fenológica de botão floral para abertura da primeira flor na posiçáo 1 do primeiro ramo frutífero, foram avaliadas: a) altura das plantas, do nível de solo até o ápice da planta; b) a altura da inserçâo do nó cotiledonar; c) espessura do caule ( $2 \mathrm{~cm}$ acima do colo da planta), com uso de paquímetro; d) área foliar determinada por meio do medidor de área foliar modelo 3100, da LICOR, USA; e e) massa da matéria seca da parte aérea, determinada após a secagem, em estufa, a $55^{\circ} \mathrm{C}\left( \pm 2{ }^{\circ} \mathrm{C}\right)$, até a obtenção da massa constante. Após obtençáo da massa da matéria seca das diferentes partes das plantas, estas foram transformadas em percentagem em relação à massa da matéria seca total das plantas, para a análise da partiçấo de assimilados.

O delineamento experimental foi o inteiramente casualizado, com 4 repetiçóes e esquema fatorial $5 \times 2$, envolvendo cinco cultivares e a embebição ou não das sementes. Os dados foram submetidos à análise de variância, e as médias comparadas pelo teste de Tukey a 5\% de probabilidade.

A análise de variância revelou efeito significativo do regulador de crescimento sobre todas as características e efeito significativo de cultivares sobre altura de plantas, altura da inserção do nó cotiledonar e área foliar.

A interaçáo cultivar vs. regulador de crescimento somente foi significativa em relação à espessura do caule (Tabela 1). Portanto, quanto às demais características, os dois fatores analisados se comportaram de forma independente.

A cultivar IAC-24, de ciclo tardio e porte alto, com maiores valores de altura de planta, altura da inserçấo do nó cotiledonar e área foliar, não diferiu de CD-405 e IPR 120, enquanto a cultivar Fibermax 966 teve os menores valores nestas características (Tabela 2). Segundo Bogiani e Rosolen (2009), quando do uso de cloreto de mepiquat, a cultivar Fibermax estava com menor estatura quando comparada com as cultivares, Delta Opal, FMT 501 e Delta Penta. York (1983) também observou que o regulador de crescimento reduz o porte das plantas do algodoeiro, com cultivares respondendo de maneira diferenciada ao uso do regulador.

A aplicação do regulador de crescimento via embebiçáo de sementes, quando comparada com a testemunha sem embebição, reduziu os valores de todas as características analisadas, comprovando que todas as cultivares são sensíveis à ação do $\mathrm{CM}$. O efeito foi maior na massa da matéria seca da parte aérea, com reduçáo de $64 \%$, contra $52 \%$ na área foliar. NAGASHIMA et al. (2005), embebendo sementes da cultivar IPR-120, obtiveram redução do porte inicial da planta, da altura da inserção cotiledonar e da área foliar.

Tabela 1. Análise de variância (valores de F) para altura de plantas, altura da inserção do nó cotiledonar, área foliar, massa da matéria seca da parte aérea e espessura do caule de plantas de algodoeiro aos 59 dias após a emergência em funçáo de cultivares e regulador aplicado nas sementes. Londrina, 2006

\begin{tabular}{lccccc} 
Fatores & $\begin{array}{c}\text { Altura de } \\
\text { plantas }\end{array}$ & $\begin{array}{c}\text { Altura inserção } \\
\text { nó cotiledonar }\end{array}$ & $\begin{array}{c}\text { Área } \\
\text { foliar }\end{array}$ & $\begin{array}{c}\text { Massa da } \\
\text { matéria seca }\end{array}$ & $\begin{array}{c}\text { Espessura } \\
\text { do caule }\end{array}$ \\
\hline Cultivares (Cv) & $4,07^{* *}$ & $6,32^{* *}$ & $0,55^{* *}$ & $0,53^{\text {ns }}$ & $1,97^{\text {ns }}$ \\
Regulador (Rg) & $127,31^{* *}$ & $143,00^{* *}$ & $3,39^{* *}$ & $5,90^{* *}$ & $24,96^{* *}$ \\
\hline CV*Rg & $1,65^{\text {ns }}$ & $2,15^{\text {ns }}$ & $0,86^{\text {ns }}$ & $0,34^{\text {ns }}$ & $2,75^{*}$ \\
C.V. $(\%)$ & 20,7 & 15,8 & 27,8 & 31,4 & 11,3
\end{tabular}

ns: năo significativo; ${ }^{*} \mathrm{e}^{* *}$ : significativo $(P<0,05$ e 0,01$)$ respectivamente. 
Quando avaliado a espessura do caule a $2 \mathrm{~cm}$ do solo, com a presença do regulador de crescimento $\mathrm{CM}$ via embebição de sementes, houve diferença somente entre a cultivar IAC-24, que obteve maior espessura, e a Fibermax 966 com a menor; não houve nenhuma diferença significativa entre as cultivares na ausência do regulador de crescimento. Somente as cultivares Fibermax 966, CD-405 e Delta Opal tiveram a espessura reduzida com o uso do regulador (Tabela 3). Entretanto, em aplicação foliar, Cordão Sobrinho et al. (2007) constataram que não houve efeito do regulador de crescimento na redução do diâmetro caulinar.

Com relação à espessura do caule, as cultivares CD 405, Delta Opal e Fibermax 966 apresentaram as maiores reduções em função da aplicação de CM, com 24,25; 17,57 e $30,08 \%$, respectivamente, quando comparadas com o não uso de regulador na semente.

As reduções verificadas nas características, acima citadas, estáo de acordo com Nagashima et al. (2005) que obtiveram resultados similares com o uso da embebição de sementes com CM com a cultivar IPR-120, cultivadas em condições de casa de vegetação e por NAGASHIMA et al. (2007) em condiçóes de campo.

Quanto à partição de assimilados (Figura 1), observou-se que com o uso do regulador de crescimento $\mathrm{CM}$ via embebiçáo de sementes, ocorreu maior percentagem na produção de folhas, principalmente na cultivar Fibermax 966, considerada mais responsiva ao regulador de crescimento CM, além da Delta Opal e CD 405, com ciclos e portes maiores. Com a redução do porte da planta, a quantidade de fotoassimilados deslocados para a produção de caules foi reduzida em todas as cultivares, sendo mais perceptível nas três cultivares anteriormente citadas. A porcentagem de assimilados nas estruturas reprodutivas aos 59 DAE comprova que, com o uso do CM, há retardamento no desenvolvimento da planta, com menor quantidade de estruturas reprodutivas produzidas; com a embebição da cultivar Fibermax 966 em CM, não ocorreu nenhuma estrutura reprodutiva nesta data (Figura 1).

Estes resultados estão de acordo com as afirmaçóes de REDDY et al. (1992), de que o uso do regulador em aplicação foliar pode reduzir o crescimento de ramos produtivos e vegetativos, bem como diminuir a área foliar devido à redução do alongamento celular. Os efeitos de mepiquat pentaborate em cultivares de algodáo de diferentes maturidades foram estudados por Johnson e PetTigrew (2006), que reforçam a percepçáo, em ensaios de competição de cultivares, de que pode ocorrer aumento do rendimento quando o regulador de crescimento é utilizado, e que as cultivares têm o potencial de diferirem em sua resposta ao uso de reguladores.

Considerando as diferenças observadas entre os genótipos quanto à sensibilidade ao regulador de crescimento CM via embebição de sementes, sobre a espessura do caule e partição de assimilados, fica evidente a necessidade de estudos subsequentes que venham contribuir para recomendaçôes específicas, de acordo com a cultivar ou grupo de cultivares.

Tabela 2. Média de altura de plantas, altura da inserção do nó cotiledonar, área foliar e massa da matéria seca da parte aérea aos 59 dias após a emergência de algodoeiro em função de cultivares e regulador aplicado nas sementes. Londrina, 2006

\begin{tabular}{|c|c|c|c|c|c|c|c|c|}
\hline Tratamentos & \multicolumn{2}{|c|}{$\begin{array}{l}\text { Altura de } \\
\text { plantas }\end{array}$} & \multicolumn{2}{|c|}{$\begin{array}{l}\text { Altura da inserção do } \\
\text { nó cotiledonar }\end{array}$} & \multicolumn{2}{|c|}{$\begin{array}{l}\text { Área } \\
\text { foliar }\end{array}$} & \multicolumn{2}{|c|}{$\begin{array}{l}\text { Matéria seca da } \\
\text { parte aérea }\end{array}$} \\
\hline Cultivares & \multicolumn{4}{|c|}{ cm } & \multicolumn{2}{|c|}{$\mathrm{cm}^{2}$} & \multicolumn{2}{|c|}{$\mathbf{g}$} \\
\hline IPR 120 & \multicolumn{2}{|c|}{$31,9 a b$} & \multicolumn{2}{|c|}{$8,4 \mathrm{a}$} & \multicolumn{2}{|c|}{$770,1 \mathrm{a}$} & \multicolumn{2}{|c|}{$6,6 a b$} \\
\hline IAC 24 & \multicolumn{2}{|c|}{$36,0 \mathrm{a}$} & \multicolumn{2}{|c|}{$8,4 \mathrm{a}$} & \multicolumn{2}{|c|}{$787,8 \mathrm{a}$} & \multicolumn{2}{|c|}{$8,3 \mathrm{a}$} \\
\hline CD 405 & \multicolumn{2}{|c|}{$29,6 a b$} & \multicolumn{2}{|c|}{$7,7 \mathrm{a}$} & \multicolumn{2}{|c|}{$692,3 \mathrm{ab}$} & \multicolumn{2}{|c|}{$7,0 \mathrm{ab}$} \\
\hline Delta Opal & \multicolumn{2}{|c|}{$31,4 \mathrm{ab}$} & \multicolumn{2}{|c|}{$7,0 \mathrm{ab}$} & \multicolumn{2}{|c|}{$708,7 \mathrm{ab}$} & \multicolumn{2}{|c|}{$6,9 a b$} \\
\hline Fibermax 966 & \multicolumn{2}{|c|}{$23,6 b$} & \multicolumn{2}{|c|}{$5,9 \mathrm{~b}$} & \multicolumn{2}{|c|}{436,2 b } & \multicolumn{2}{|c|}{$5,0 \mathrm{~b}$} \\
\hline DMS & \multicolumn{2}{|c|}{9,2} & \multicolumn{2}{|c|}{1,7} & \multicolumn{2}{|c|}{272,6} & \multicolumn{2}{|c|}{3,1} \\
\hline Regulador & $\mathrm{cm}$ & CR (\%) & $\mathrm{cm}$ & CR (\%) & $\mathrm{cm}^{2}$ & CR (\%) & g & CR (\%) \\
\hline Sem & 41,8 & 100 & 9,7 & 100 & 916,5 & 100 & 9,9 & 100 \\
\hline Com & 19,3 & 46 & 5,3 & 55 & 441,6 & 48 & 3,6 & 36 \\
\hline DMS & 4,1 & & 0,8 & & 121,5 & & 1,4 & \\
\hline
\end{tabular}

Médias seguidas de letras iguais na coluna não diferem entre si pelo teste de Tukey em nível de $5 \%$ de probabilidade; $\mathrm{CR}=$ crescimento relativo.

Tabela 3. Espessura média de caule $(\mathrm{mm})$ de plantas de algodoeiro de diferentes cultivares originadas de sementes embebidas e não em solução de CM, aos 59 dias após emergência. Londrina, 2006

\begin{tabular}{|c|c|c|c|}
\hline \multirow{3}{*}{ Cultivares } & \multicolumn{3}{|c|}{ Espessura do caule } \\
\hline & Sem regulador & Com regulador & DMS \\
\hline & & mm & \\
\hline IPR-120 & $5,68 \mathrm{~A} a$ & $5,55 \mathrm{~A} a b$ & \\
\hline IAC-24 & $6,50 \mathrm{~A} a$ & $6,10 \mathrm{~A} a$ & \\
\hline CD-405 & $6,70 \mathrm{~A} a$ & $5,08 \mathrm{~B}$ ab & 0,95 \\
\hline DELTA OPAL & $6,43 \mathrm{~A} a$ & $5,30 \mathrm{~B}$ ab & \\
\hline FIBERMAX 966 & $6,40 \mathrm{~A} \mathrm{a}$ & 4,48 B b & \\
\hline DMS & 1,35 & 1,35 & \\
\hline
\end{tabular}

Letras iguais maiúsculas nas linhas e minúsculas nas colunas, nâo diferem pelo teste de Tukey em nível de 5\% de probabilidade. 


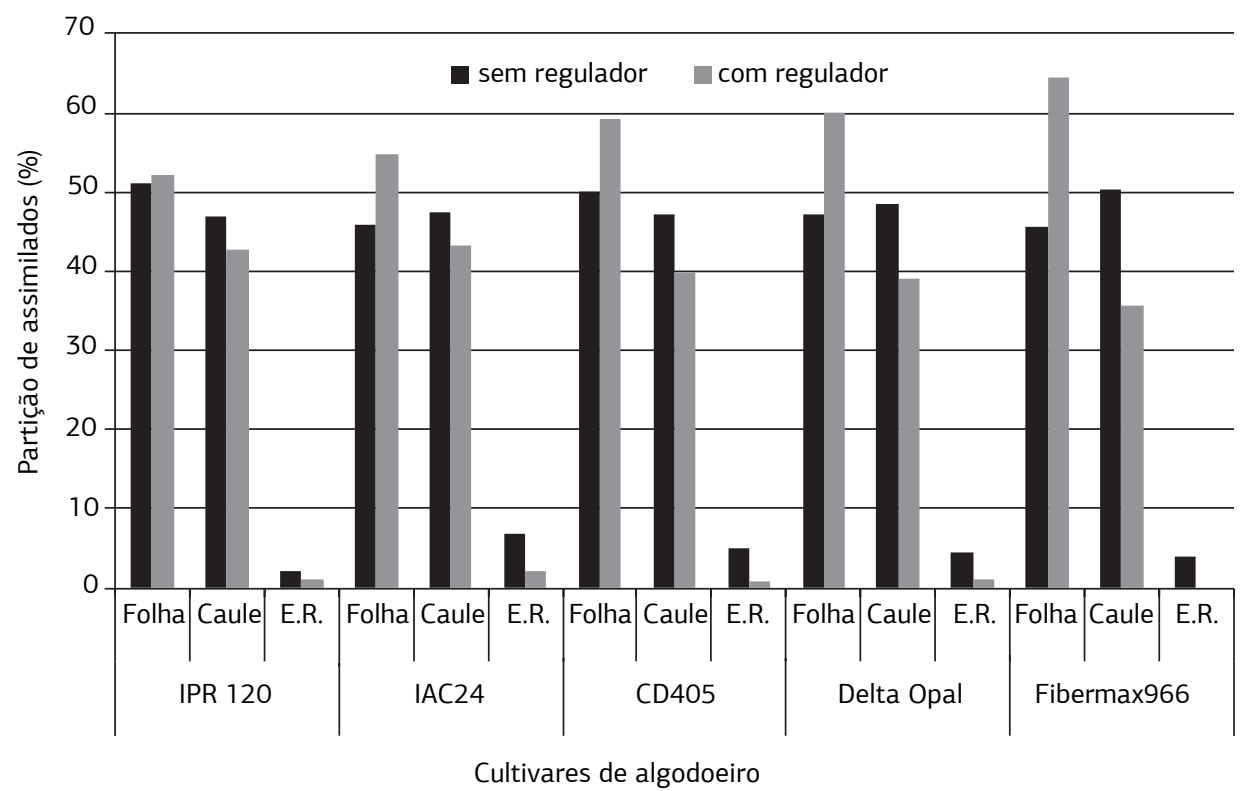

Figura 1. Partição de assimilados (\%) de folhas, caules e estruturas reprodutivas (E.R.) em plantas de diferentes cultivares de algodoeiro originadas de sementes embebidas em solução de CM em relação à não-embebidas, aos 59 dias após emergência. Londrina, 2006.

Em conclusão, as cultivares respondem diferentemente ao $\mathrm{CM}$, quando aplicado via embebiçáo de sementes, com grande redução na altura de planta, altura da inserçâo do nó cotiledonar, área foliar e massa da matéria seca. Há alteração na partiçáo de assimilados, e as cultivares Fibermax 966, Delta Opal e CD 405 foram mais sensíveis à aplicação de $\mathrm{CM}$ quanto à espessura do caule e à partição de assimilados.

\section{AGRADECIMENTOS}

À Coordenação de Aperfeiçoamento de Pessoal de Nível Superior (CAPES), pela concessão de bolsa de estudo ao primeiro autor.

\section{REFERÊNCIAS}

BOGIANI, J.C.; ROSOLEN, C.A. Sensibilidade de cultivares de algodoeiro ao cloreto de mepiquat. Pesquisa Agropecuária Brasileira, v.44, p.1246-1253, 2009.

CORDÃO SOBRINHO, F.P.; FERNANDES, P.D.; BELTRÃO, N.E.M.; SOARES, F.A.L.; TERCEIRO NETO, C.P.C. Crescimento e rendimento do algodoeiro BRS-200 com aplicações de cloreto de mepiquat e lâminas de irrigação. Revista Brasileira de Engenharia Agrícola Ambiental, v.11, p.284-292, 2007.

CORBIN JR., B.R.; FRANS, R.E. Protecting cotton (Gossypium hirsutum) from Fluometuron injury with seed protectants. Weed Science, v.39, p.408-411, 1991.

JOHNSON, J.T.; PETTIGREW, W.T. Effects of mepiquat pentaborate on cotton cultivars with different maturities. Journal of Cotton Science, v.10, p.128-135, 2006.
LAMAS, F.M.; ATHAYDE, M.L.F.; BANZATTO, D.A. Reaçôes do algodoeiro CNPA-ITA 90 ao cloreto de mepiquat. Pesquisa Agropecuária Brasileira, v.35, p.507-516, 2000.

LAMAS, F.M. Cloreto de mepiquat na cultura do algodoeiro via sementes. In: Boletim de Pesquisa e Desenvolvimento 33, 2006, Dourados: Embrapa Agropecuária Oeste, 19 p., 2006. Disponível em:<http://www.cpao.embrapa.br/publicacoes/ ficha.php? tipo $=B P \&$ num $=33 \&$ ano $=2006>$. Acesso em: 3 nov. 2007.

NAGASHIMA, G.T.; MARUR, C.J.; YAMAOKA, R.S.; MIGLIORANZA, É. Desenvolvimento de plantas de algodão provenientes de sementes embebidas com Cloreto de Mepiquat. Pesquisa Agropecuária Brasileira, v.40, p.943-946, 2005.

NAGASHIMA, G.T.; MIGLIORANZA, É.; MARUR, C.J.; YAMAOKA, R.S.; GOMES, J.C. Embebição de sementes e aplicação foliar com cloreto de mepiquat no crescimento e produção do algodoeiro. Ciência e Agrotecnologia, v.31, p.10271034, 2007.

O'BERRY, N.B.; FAIRCLOTH, J.C.; JONES, M.A.; HERBERT JR., D.A.; ABAYE, A.O.; McKEMIE, T.E.; BROWNIE, C. Diferencial responses of cotton cultivars when applying mepiquat pentaborate. Agronomy Journal, v.101, p.25-31, 2009.

REDDY, V.R.; TRENT, A.; ACOCK, B. Mepiquat chloride and irrigation versus cotton growth and development. Agronomy Journal, v.84, p.930-933, 1992.

YORK, A.C. Cotton cultivar response to mepiquat chloride. Agronomy Journal, v.75, p. 663-667, 1983.

ZANQUETA, R.; FURLANI JUNIOR, E.; PANTANO, A.C.; SOUZA, R.A.R. Modos de aplicação de regulador de crescimento com diferentes densidades de plantas em cultivares de algodáo herbáceo (Gossypium hirsutum L. var. latifolium Hutch.) Acta Scientiarum. Agronomy, v.26, p.97-105, 2004. 